Harrison S. Weisinger', James A. Amnitage ${ }^{2 s}$, Andrew J. Sinclair', Algis J. Vingrys',

Peta L. Burns' \& Richard S. Weisinger?

'Department of Food Science,

Royal Melbourne Institute of

Technology University

Melbourne, Victoria, Australia

${ }^{z}$ Howard Florey Institute of Experimental

Physiology and Medicine and

'Department of Optometry and Vision Sclences,

University of Melbourne, Pankville, Victoria,

Australia

Email: harrison.weisinger $\oplus_{\text {mit.edu.au }}$
1. Barker, D.J., Bull, A.R., Osmond, C. \& Simmonds, SJ. Fetal and placental size and risk of hypertension in adult life. Br. Med. J. 301, 259-262 (1990).

2. Meaney. M.J. et al. Early ervironmental regulation of forebrain glucocorticoid receptor gene expression: implications for adrenocortical responses to stress. Dev. Neurosci. 18, 49-72 (1996).

3. Lengley-Evans, S.C., Clamp, A.G., Grimble, R.F. \& Jackson, A.A. Influence of dietary fats upon systolic blood pressure in the rat. Int. J. Food Sci. Nutr. 47. 417-425 (1996).

4. Morris, M.C., Sacks, F. \& Rosner, B. Does fish oil lower blood pressure? A meta-analysis of controlled trials. Circulation 88, 523-533 (1993).

5. Fenton, W.S., Hibbeln, J.R. \& Knable, M. Essential fatty acids, lipid membrane abnormalities, and the diagnosis and treatment of schizophrenia. Biol.
Psych, 47, 8-21 (2000)

6. Weisinger, H.S., Vingrys, A.J., Bui, B.V. \& Sinclair, AJ. Effects of dietary n-3 fatty acid deficiency and repletion in the guines pig retina. Imvest. Ophthalmol. Visua/ Sci. 40, 327-338 (1999).

7. Repp, J.P. Dehl selt-susceptible and salt-resistant rats. A review. Hypertension 4, 753-63 (1982)

8. Weisinger, H.S., Vingrys, A.J. \& Sinclair, A.J. Dietary manipulation of long-chain polyunsaturated fatty acids in the retina and brain of guinee pigs. Lipids 30, 471-473 (1995).

9. Denton, D.A., McKinley, M.J. \& Weisinger, R.S. Hypothalamic integration of body fluid regulation. Proc. Natl. Acad Sci. USA 93, $7397-7404$ (1996).

10. Granger, J.P. \& Schnackenberg, C.G. Renal mechanisms of angiotensin II-induced hypertension. Semin. Nephrol. 20, 417-425 (2000).

\title{
Countering the 'counterattack' hypothesis
}

To the editor-In this issue, O'Connell et al. suggest that Fas ligand (FasL) mediates immune privilege by protecting tumors or tissues from immune attack, but we maintain that there is no convincing evidence of this. We would also like to re-emphasize our views of FasL: contrary to the suggestion of O'Connell and colleagues, we do not regard FasL as "solely a mediator of inflammation", but instead, find that Fas and its ligand are involved in target cell killing and immune cell homeostasis, especially as mediators of activation induced cell death in T-cells ${ }^{2}$. Although there can be differences of opinion, there are a number of important studies omitted from this commentary crucial to the interpretation of evidence supporting the 'FasL counterattack' hypothesis ${ }^{1}$.

We caution against any dismissal of concerns about scientific methods and reagents ${ }^{1}$. Faulty reagents have been and continue to be a significant source of error ${ }^{2}$. The antibodies used in many studies have been clearly shown to lack specificity ${ }^{3}$. This is especially the case for the monoclonal antibody mAb33 from Transduction Labs, which stains CD95L-transfected and untransfected cells to a similar extent, labels tissue sections that lack CD95L mRNA and stains a protein by 2D-electrophoresis with a different mobility than FasL. A similar lack of specificity has been observed for both the $\mathrm{C}-20$ and $\mathrm{N}-20$ antibodies from Santa Cruz Biotechnology. The validity of functional assays, especially those using Jurkat cell death, have been challenged by otherst.

Well-controlled work in experimental animals clearly indicates that engineered expression of FasL on tumors or transplanted tissues actually results in accelerated rejection, rather than immune privilege $\mathrm{e}^{2,5}$. Though FasL-mediated inflammation can be abrogated through a variety of means, animal studies simply do not demonstrate that conferring FasL expression to a tumor or a tissue grants it immune privilege. In fact, one promising new use for FasL is to induce inflammation and immunity $y^{6,7}$.

Clinical data is used to support the case that FasL expression by tumors correlates with disease progression and or with poor prognosis ${ }^{1}$. Several studies omitted from the analysis in this issue ${ }^{1}$ are inconsistent with this hypothesis ${ }^{8,0}$.

Although mounting experimental evidence has indicated that FasL does not play a role in immune privilege in the testis ${ }^{10}$, many still support the possibility of FasL-mediated immune privllege in the eye. A team lead by Caspi recently found that neither lack of Fas nor lack of FasL on ocular tissue alters eye pathology in a model of experimental autoimmune uveitis ${ }^{11}$. Also, if FasL expression in the eye was critical for the maintenance of immune privilege, patients with autoimmune lymphoproliferative syndrome, who cannot signal through Fas, would be expected to have ocular immune dysfunction, but they do not (J. Puck, pers. comm. and ref. 12). Thus, reports of FasL-mediated immune privilege in the eye do not appear to have clinical corroboration.

Thus, if one takes into account all of the experimental data, one may conclude that the body of evidence supporting a role for FasL in immune privilege is lacking. Thomas Huxley once lamented: "The great tragedy of science-The slaying of an original, beautiful hypothesis by an ugly fact."
Nicholas P. Restifo

National Cancer Institute

National Institutes of Health

Bethesda, Maryland

email: restifo@inih.gov

1. O'Connell, J.4 Houston, A., Bennett, M.W., O'Sullivan, G.C. \& Shanahan, F. Immune privilege or inflammation? Insights into the Fas ligand enigma. Nature Med 7. 271-274 (2001).

2. Restifo, N.P. Not so Fas: Re-evaluating the mechenisms of immune privilege and tumor escape. Nature Med. 6, 493-495 (2000).

3. Fiedler, P., Schaetzlein, C.E. \& Eibel, H. Constitutive expression of FasL in thyrocytes. Science 279, 2015a (1998).

4. Favre-Felix, N. et al. Cutting edge: the tumor counterattack hypothesis revisited: colon cancer cells do not induce Tœll apoptosis via the Fas (CD95, APO1) pathway. J. Immunol. 164, 5023-5027 (2000).

5. Kang, S.M. ot al. Fas ligand expression in islets of Langerhans does not confer immune privilege and instead targets them for rapid destruction. Nature Med. 3, 738-743 (1997).

6. Rescigno, $\mathrm{M}$. et $a$ l. Fas engagement induces the maturation of dendritic cells (DCs), the release of interleukin (IL)-1 B, and the production of interferon $\gamma$ in the absence of IL-12 during DC-T cell cognate interaction. A new role for fas ligand in inflammatory responses. \& Exp. Med. 192, 1661-1668 (2000).

7. Restifo, N.P. Building better vaccines: How apoptotic cell death can induce inflammation and activate innate and adaptive immunity. Curr. Opin. inmunol. 12, 597-603 (2000).

8. Ragnarsson, G.B. et al. Intracellular fas ligand in normal and malignent breast epithelium does not induce apoptosis in fas-sensitive cells [in process citation]. Br. $\&$ Cancer. 83, 1715-1721 (2000).

9. Basolo, F. et al. Suppression of Fas expression and down-regulation of Fas ligand in highly aggressive human thyroid carcinoma. Lab. Investig. 80, 1413-1419 (2000).

10. Alison, J., Georgiou, H.M., Strasser, A. \& Vaux, D.L. Transgenic expression of CD95 ligand on islet Bcells induces a granulocytic infiltration but does not confer immune privilege upon islet allografts. Proc. Natt. Acad. Sci USA 94, 3943-3947 (1997).

11. Wahtsten, J.L., Gitchell, H.L., Chan, C.C., Wiggert, B. \& Caspi, R.R. Fas and fas ligand expressed on cells of the immune system, not on the target tissue, control induction of experimental autoimmune uveitis. $l$ Immunol. 165, 5480-5486 (2000) .

12. Straus, S.E., Sneller, M., Lenardo, M J., Puck, J.M. \& Strober, W. An inherited disorder of lymphocyte apoptosis: the autoimmune lymphoproliferative syndrome. Ann. Intern. Med. 130, 591-601 (1999) 